\title{
Membrane adsorber with hierarchically porous HKUST-1 immobilized in membrane pores by flowing synthesis
}

\author{
Ke Bai ${ }^{1}$, Senqing Fan ${ }^{1}$, Yu Chen ${ }^{1}$, Yilin Wang ${ }^{1}$, Jiaojiao Chen ${ }^{1}$, Zenghui Mai ${ }^{1}$, Jingyun \\ $\mathrm{Liu}^{1}$, Lei Deng ${ }^{1}$, and Zeyi Xiao ${ }^{1}$ \\ ${ }^{1}$ Sichuan University
}

December 22, 2021

\begin{abstract}
A membrane adsorber with hierarchically porous HKUST-1 (HP-HKUST-1) immobilized in membrane pores has been fabricated by flowing synthesis. The XRD characteristics indicated that the structure integrity of the HP-HKUST-1 immobilized in the membrane pores can be kept after template agent removed. Other characteristics presented by XPS, FTIR, SEM, TEM and BET proved the effective immobilization of HP-HKUST-1 in membrane pores. Compared with hydrothermal HKUST-1 powder, the adsorption capacity for Congo red and Methylene blue adsorption can be increased several times by hydrothermal HP-HKUST-1 powder, owing to the mesopores with rich active sites for adsorption. When the solution was flowed through the membrane adsorber, the adsorption rate for these adsorbates increased significantly, owing to the enhanced mass transfer in the confined space of the membrane pores with micro or nano scale. After going through seven adsorption-desorption experiments, the membrane adsorber with HP-HKUST-1 immobilized in membrane pores shows a remarkable repeatability.
\end{abstract}

Membrane adsorber withhierarchically porous HKUST-1 immobilized in membrane pores by flowing synthesis

Ke Bai, Senqing Fan*, Yu Chen, Yilin Wang, Jiaojiao Chen, Zenghui Mai, Jingyun Liu, Lei Deng, Zeyi Xiao School of Chemical Engineering, Sichuan University, 610065, Chengdu, China

*Email: fansenqing86@scu.edu.cn, Tel/Fax number: 86-028-85405220

\begin{abstract}
A membrane adsorber with hierarchically porous HKUST-1 (HP-HKUST-1) immobilized in membrane pores has been fabricated by flowing synthesis. The XRD characteristics indicated that the structure integrity of the HP-HKUST-1 immobilized in the membrane pores can be kept after template agent removed. Other characteristics presented by XPS, FTIR, SEM, TEM and BET proved the effective immobilization of HP-HKUST-1 in membrane pores. Compared with hydrothermal HKUST-1 powder, the adsorption capacity for Congo red and Methylene blue adsorption can be increased several times by hydrothermal HP-HKUST-1 powder, owing to the mesopores with rich active sites for adsorption. When the solution was flowed through the membrane adsorber, the adsorption rate for these adsorbates increased significantly, owing to the enhanced mass transfer in the confined space of the membrane pores with micro or nano scale. After going through seven adsorption-desorption experiments, the membrane adsorber with HP-HKUST-1 immobilized in membrane pores shows a remarkable repeatability.
\end{abstract}

Key words: metal-organic frameworks; membrane adsorber; flowing synthesis; hierarchically porous structure

\section{Introduction}


Metal-organic framework materials (MOFs) are a kind of organic-inorganic hybrid porous materials synthesized by metal ion clusters and organic ligands through coordination ${ }^{1,2}$. They are good adsorbents owing to easy synthesis, diverse structures, large specific surface area, and easy functional modification of pore surface $^{3,4}$. In addition, the structure and pore properties of MOFs can be precisely tuned according to the property of the adsorbate, which shows great potential in adsorption. However, most MOFs reported only have a microporous structure ${ }^{5,6}$. Thus, the macromolecules as adsorbate can hardly reach the adsorption active sites at the internal cave of the MOFs and the diffusion of adsorbate could be weakened, which limits the application of $\mathrm{MOFs}^{7,8}$. It has been reported that the fabrication of lattice vacancies can produce the mesopores and macrospores in the bulk MOFs ${ }^{9}$. The MOFs with hierarchical porous structure can improve the diffusion of adsorbate in MOFs and provide more active sites for adsorption.

Currently, the hierarchically porous MOFs (HP-MOFs) is widely fabricated by template synthesis, in which the template agents are applied during the synthesis of MOFs and the mesoporous structure can be achieved by removing the template agents ${ }^{10}$. Compared with other methods, the template synthesis can conveniently regulate the size, morphology and structure of HP-MOFs, owing to the spatial confinement and the adjustment of the template agent ${ }^{11}$. For instance, Cai et al. used organic acids with long alkyl chains as soft template agents to prepare HP-UiO-66 and better adsorption performance for dye adsorption could be achieved $^{12}$.

The separation and recovery process are required, if the powdered MOFs is expected to applied in industry ${ }^{13}$. Porous membrane is the good carrier for MOFs immobilization, since it has a tortuous pore structure and uniform pore size distribution, as well as diverse preparation methods ${ }^{14}$. Immobilizing MOFs in membrane pores to fabricate membrane adsorber can uniformly disperse MOFs and the aggregation beyond the membrane pores can be prevented. Besides, the curved pore structure of membrane can improve the stability of MOFs and the detaching of the MOFs particles from the membrane pores can be avoided ${ }^{15}$. Furthermore, from the perspective of adsorption kinetics, enhanced mass transfer can be achieved owing to the confined space effect of membrane pores during the adsorption process with membrane adsorber as flowing through mode, since the distance of mass transfer is reduced to micro or nano scale. Therefore, the improvement of adsorption rate can be expected by membrane adsorber ${ }^{16}$.

In our previous study, flowing synthesis has been developed to immobilize the MOFs particles in membrane pores ${ }^{16-22}$. During this process, the precursor solution of the MOFs particles is flowing through the membrane by an external force and the MOFs particles can be fabricated and immobilized in membrane pores simultaneously. As a result, enhanced catalytic or adsorption performance can be achieved by this membranes ${ }^{23}$. HKUST-1, with regular octahedron structure, good water, chemical stability and rich active adsorption active sites, is a kind of adsorbent with good performance ${ }^{24}$. Enhanced adsorption performance can be expected by hierarchically porous HKUST-1 (HP-HKUST-1). In this study, HP-HUST-1 will be immobilized in membrane pores for the assembly of membrane adsorber by combing flowing synthesis and template agent removal. The adsorption for MB and CR is carried out to evaluate the adsorption performance of the membrane adsorber. The effect of the concentration of dyes and the flowrate and the mass of MOFs on adsorption are also studied.

\section{Materials and Methods}

\subsection{Materials}

The Polyethersulfone (PES) porous membrane with a mean pore size of $0.45 \mu \mathrm{m}$, porosity of 0.7 and thickness of 100-150 $\mu \mathrm{m}$ is provided by Chuangwei Filter Materials Company. Cupric(II) nitrate trihydrate $\left(\mathrm{Cu}\left(\mathrm{NO}_{3}\right)_{2} \cdot 3\left(\mathrm{H}_{2} \mathrm{O}\right)\right.$, Methyl Blue (MB), Congo Red $(\mathrm{CR})$, ethanol and methanol are purchased from Kelong Chemical Company. N,N,N,N-tetramethyl-1,6-hexanediamine and 1, 3, 5-benzenetricarboxylic acid are purchased from Aladdin. All the reagents are analytical grade purity used as received without further treatment.

\subsection{Assembly of membrane adsorber}


The schematic diagram of the membrane adsorber assembling is shown inFigure $\mathbf{1}$. The PES membrane is immersed in ethanol to remove impurities before the immobilization of HP-HKUST-1 in membrane pores. After that, the $\mathrm{Cu}\left(\mathrm{NO}_{3}\right)_{2}$ solution $\left(3.64 \mathrm{~g} \mathrm{Cu}\left(\mathrm{NO}_{3}\right)_{2} \cdot 3\left(\mathrm{H}_{2} \mathrm{O}\right)\right.$ dissolved in $100 \mathrm{~mL}$ deionized water $)$ is permeated through the membrane pores. Then, the membranes were transferred into a vacuum oven and dried at $60{ }^{\circ} \mathrm{C}$ for 30 min. Then, 1, 3, 5-benzenetricarboxylic acid solution mixed with $\mathrm{N}, \mathrm{N}, \mathrm{N}, \mathrm{N}$-tetramethyl-1, 6hexanediamine (1.75 g 1,3,5-benzenetricarboxylic acid and $3.86 \mathrm{~g} \mathrm{~N}, \mathrm{~N}, \mathrm{~N}, \mathrm{~N}$-tetramethyl-1, 6-hexanediamine dissolved in methanol) was permeated through the membranes, followed by drying the membrane at $60{ }^{\circ} \mathrm{C}$ for 30 min. Repeating the above two processes the required HKUST-1 particles can be immobilized in membrane pores, named as HKUST-1/PES membrane. At last, the membrane was placed in the ultrasonic cleaner for washing off the unstable nanoparticles. In order to obtain the HP-HKUST-1 in membrane pores, the HKUST-1/PES membrane was placed into an oven overnight with temperature kept at $393 \mathrm{~K}$ for N, N, N, N-tetramethyl-1, 6-hexanediamine removal. In addition, the hydrothermally synthesized HKUST-1 and HP-HKUST-1 powder were also prepared, with the prepared method described in supporting information.

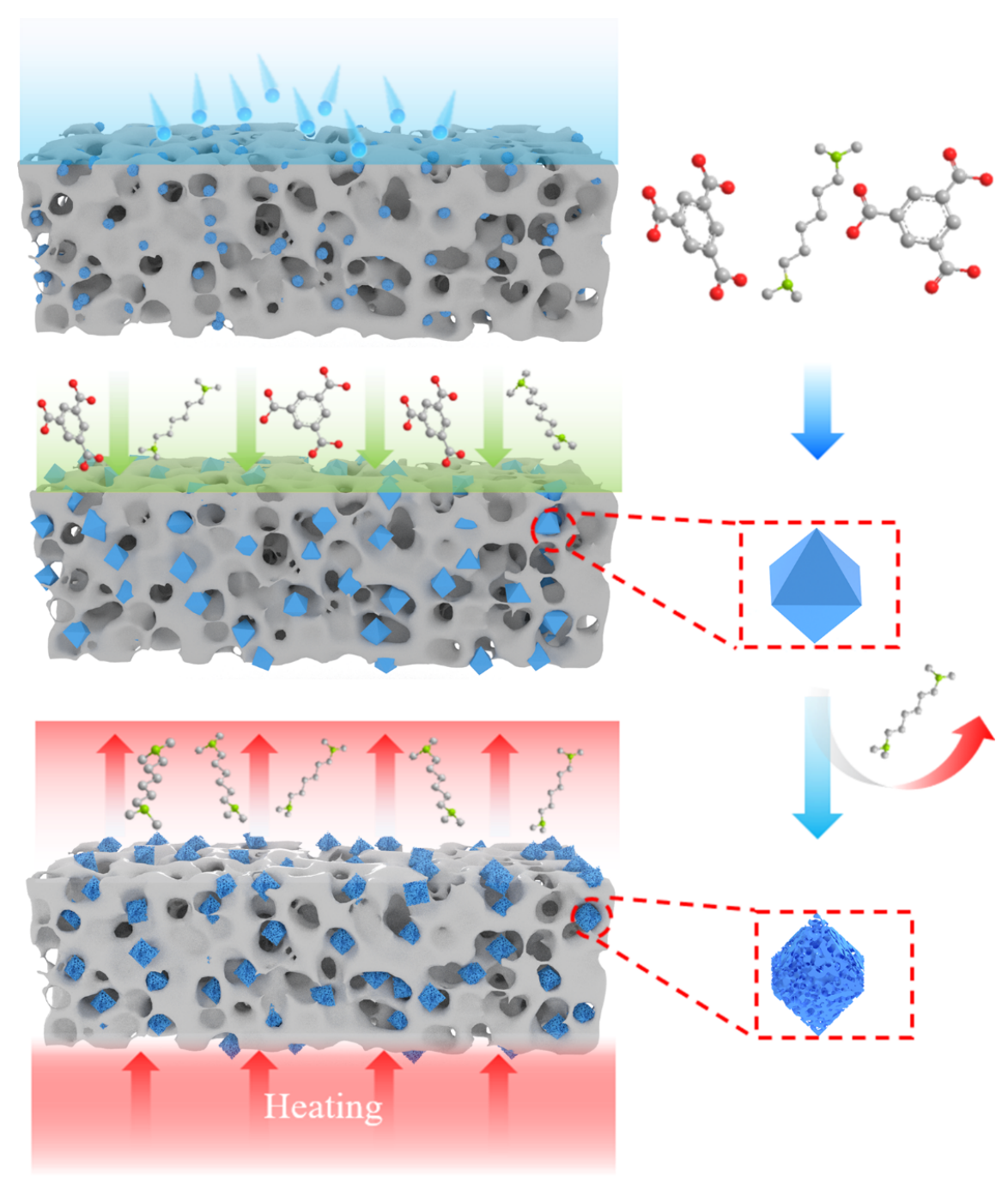

Figure 1. Schematic diagram of fabricating membrane adsorber with flowing synthesis.

\subsection{Adsorption experiment}


The adsorption experiments of CR and MB solutions by HP-HKUST-1/PES membrane and HP-HKUST1 powder is carried out by batch and continuous adsorption, as shown in Figure 2 . HKUST-1/PES membrane and HP-HKUST-1/PES membrane are used as adsorbents and fixed in the membrane module. In the batch adsorption, the adsorption liquid is stirred by a magnetic stirrer with constant speed. In continuous adsorption, the entire unit is connected by a flexible pipe to form a circulating system. The pre-prepared dye solution is forced to be fed into the membrane module fixed with membrane adsorber. The effective area of the membrane in the membrane module is $0.00047 \mathrm{~m}^{2}$.

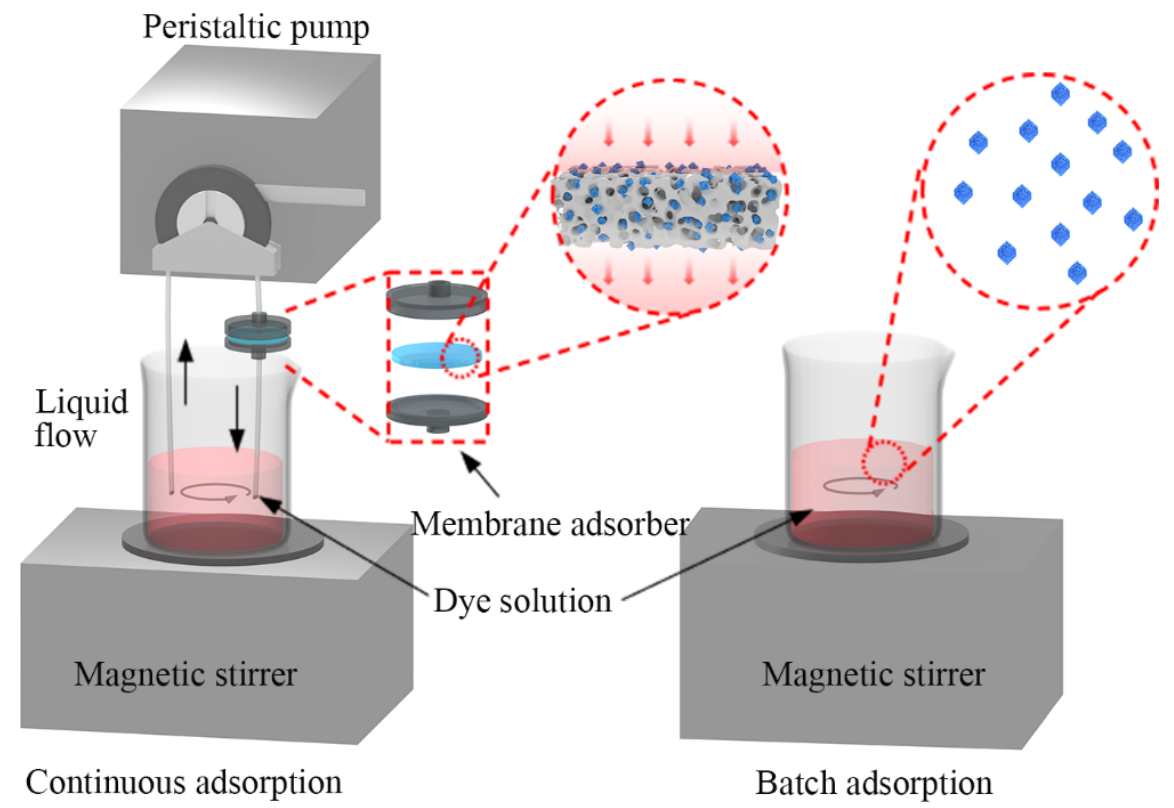

Figure 2. Diagram of adsorption process by membrane adsorber under the flow-through mode (A) and the HP-HKUST-1 powders through batch adsorption (B).

\section{Results and discussion}

\subsection{Characterization of membrane adsorber}

In order to demonstrate the successful assembly of HP-HKUST-1 in the pores of the PES membrane, the membrane adsorber with HP-HKUST-1 is characterized. Figure 3(A) shows the XRD spectra of membrane adsorber with HP-HKUST-1 immobilized, which are consistent with the simulation results. The results indicated that HP-HKUST-1 has been successfully immobilized in membrane pores. Besides, no difference of the XRD pattern between the HKUST-1/PES membrane and HP-HKUST-1/PES membrane implied that the addition of organic amine does not affect the crystal structure of HP-HKUST-1. It can be seen that the peak intensity of HP-HKUST-1/PES membrane is not as strong as that of HKUST-1/PES membrane, since the effect of organic amines and lattice defects may lead to the reduced crystallinity of HP-HKUST1. From the TGA results as shown in Figure S1, it can be also seen that compared with HKUST1/PES membrane, an additional weight loss in the range of $170-270{ }^{\circ} \mathrm{C}$ for HP-HKUST-1/PES membrane owing to the removal of the ligand N,N,N,N-tetramethylhexanediamine. This phenomenon implied that the introduction of organic amines during the process of immobilizing HP-HKUST-1 is successfully. The FTIR characteristics of membrane adsorber with HP-HKUST-1 immobilization are shown in Figure 3(B) . It can be seen that the antisymmetric stretching vibration absorption peak of the carboxylate appears at 1577 $\mathrm{cm}^{-1}$, the symmetric stretching vibration absorption peaks of the carboxylate appears at 1442 and $1364 \mathrm{~cm}^{-1}$, and the stretching vibration absorption peak of $\mathrm{Cu}-\mathrm{O}$ bond appears at $762 \mathrm{~cm}^{-1}$. It is worth mentioned that the absorption peak of $\mathrm{Cu}-\mathrm{N}$ bond at $431 \mathrm{~cm}^{-1}$ may be difficult to distinguish due to the coverage by the out-of-plane wobble vibration absorption peak of $\mathrm{COO}^{-}$, etc. as well as its weak spectral absorption peak ${ }^{25}$. 
The XPS characteristics of membrane adsorber with HP-HKUST-1 immobilized are shown in Figure 3 (C, D) . Compared with HKUST-1/PES membrane, a new $\mathrm{Cu}-\mathrm{N}$ characteristic peak appears at $401.9 \mathrm{eV}$ and the peak of $\mathrm{N} 1 \mathrm{~s}$ orbital belonging to $\mathrm{Cu}-\mathrm{N}$ shifts $0.4 \mathrm{eV}$ to the high binding energy for the HP-HKUST1/PES membrane, as shown in Figure 3C. Besides, the peak of $\mathrm{Cu} 2 \mathrm{p}_{3 / 2}$ orbital shifts $0.7 \mathrm{eV}$ to the low binding energy, as shown in Figure 3D . These phenomena implied that HP-HKUST-1 has been successfully immobilized in PES membrane pores.
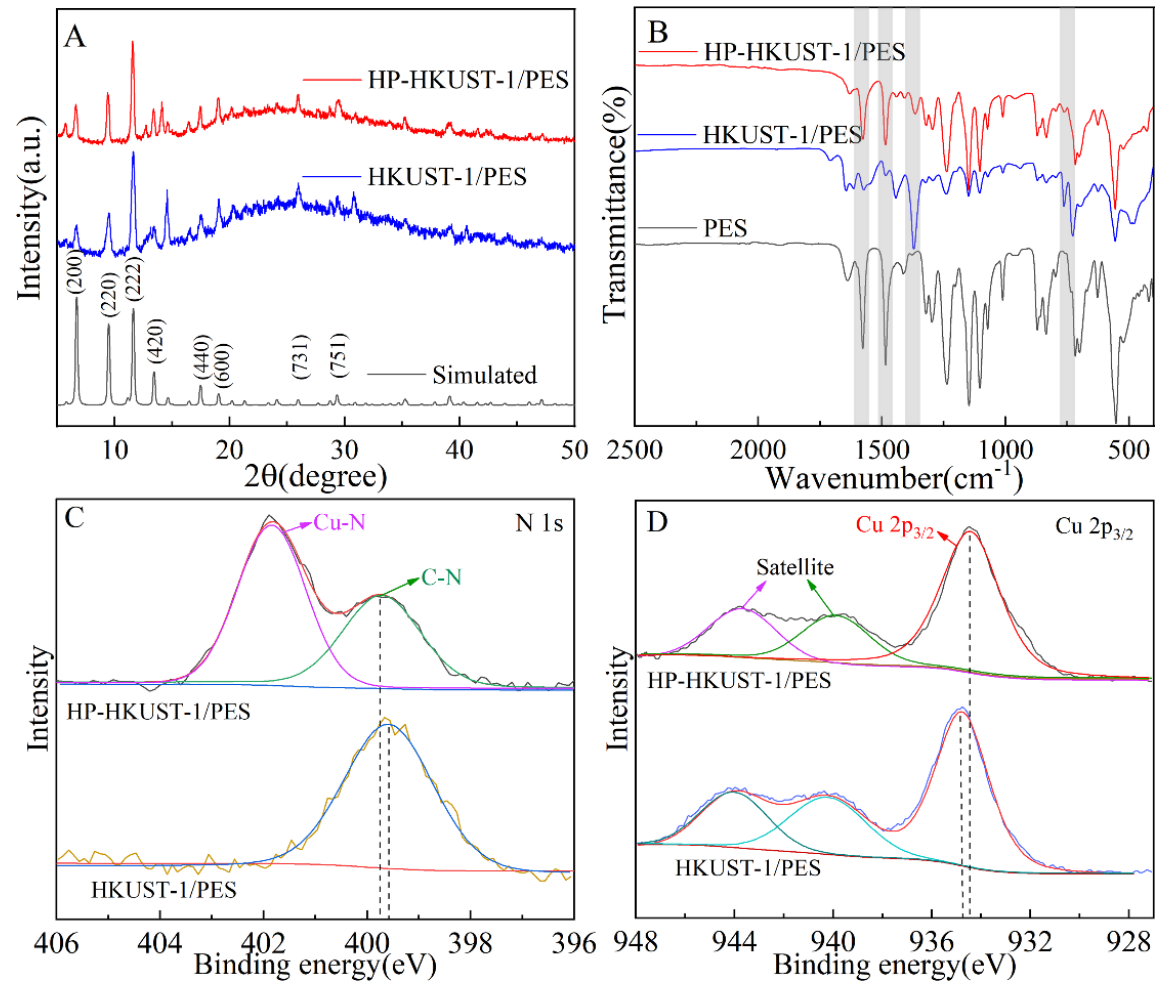

Figure3 . Characterization of HP-HKUST-1/PES membrane (A: XRD; B: FTIR; C: high-resolution XPS spectrum of $\mathrm{N} 1 \mathrm{~s} ; \mathrm{D}$ : high-resolution XPS spectrum of $\left.\mathrm{Cu} 2 \mathrm{p}_{3 / 2}\right)$.

The morphology and distribution of HP-HKUST-1 in PES membrane have been determined by SEM, as shown in Figure 4. It can be seen that the nanoparticles are effectively immobilized in the pore of the PES membrane with the membrane fiber wrapped by the nanoparticles. Besides, the size of the nanoparticles immobilized in membrane pores are uniform with it value in the range of $1000 \pm 200 \mathrm{~nm}$. From Figure 4(B), it can be seen that some pores are shown in the nanoparticles and a hierarchical pore structure of HP-HKUTS-1 are successfully fabricated in PES membrane pores by flowing synthesis. More visual and definitive morphologies of the porous structure of HP-HKUST-1 were observed in TEM image (Figure S2A ). From the optical image of the HP-HKUST-1 as shown in Figure S2B , it can be seen that the color of the membrane adsorber is uniform, which implied that the nanoparticles are immobilized in each pore of the PES membrane. Besides, the EDS scan shows the elemental distribution of the whole cross section of HP- HKUST-1/PES membrane, and it can be seen that $\mathrm{C}, \mathrm{N}, \mathrm{O}, \mathrm{Cu}$ are uniformly distributed along the thickness direction throughout the cross section with the uniform distribution of the HP- HKUST-1 along the direction of membrane thickness can be expected. Combining the results from the optical image and EDS, it can be deduced that the HP-HKUST-1 is immobilized uniformly both along the surface direction and thickness direction of PES porous membrane. 

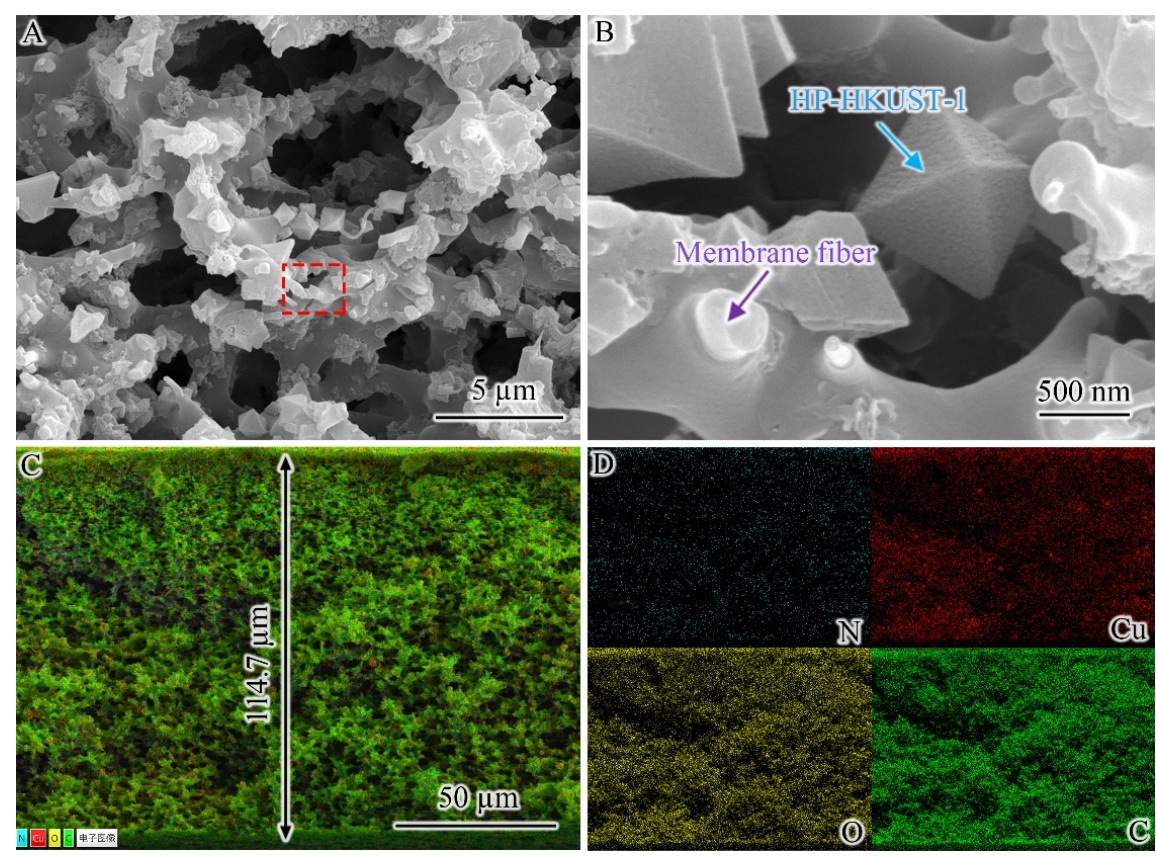

Figure 4 . The morphology of HP-HKUST-1/PES membrane (A, B: SEM images of the membrane crosssection; C, D: EDS analysis).

The size of the hierarchical pore structure and the specific surface area of the HP-HKUST-1/PES membrane are determined by the BET analysis with the results shown in Figure 5(A). It can be seen that the $\mathrm{N}_{2}$ adsorption-desorption isotherm of the HP-HKUST-1/PES membrane shows a classical I curve ${ }^{26}$. The isotherm of HKUST-1/PES membrane demonstrate a typical microporous adsorption characteristic at a relative pressure of $\mathrm{P} / \mathrm{P} 0<0.8$ and the quantity adsorbed increased rapidly if a relative pressure of $\mathrm{P} / \mathrm{P} 0>0.8$, since the mesopores and marcopores between the nanoparticles are existed. In contrast, the $\mathrm{N}_{2}$ adsorption-desorption isotherm of HP-HKUST-1/PES membrane shows a classical type IV with a wide hysteresis loop, indicating the presence of abundant microporous structures and mesoporous structure ${ }^{27}$. At low relative pressures of $\mathrm{P} / \mathrm{P} 0<0.4$, monolayer adsorption dominates and the adsorption capacity increases rapidly to saturation due to the high adsorption capacity of the abundant microporous structure. At high relative pressures of $\mathrm{P} / \mathrm{P} 0>0.4$, multilayer adsorption and mesoporous adsorption appears, and the adsorption capacity increased again after saturation. Also, a significant hysteresis loopback exists in the desorption process, owing to the capillary coalescence of $\mathrm{N}_{2}$ molecules in the mesopores. The closure of the adsorption-desorption isothermal curve indicates that no close pores exited in HKUST-1/PES membrane with stable pore structure. Besides, it can be deduced that compared with HKUST-1/PES membrane, a richer and more tunable layered porous structure for HP-HKUST-1/PES membrane is performed. From Figure 5(B), it can be seen that the HP-HKUST-1/PES membrane contains a wide pore size distribution range from 8 to $40 \mathrm{~nm}$ not observed in the HKUST-1/PES membrane, except for micropores with diameters of 0.8-1.2 nm. The specific surface areas and pore volumes of HKUST-1 membrane and HP-HKUST-1 membrane are illustrated in Table 1 . It can be seen that the volume of the mesopores increased significantly, if the membrane is immobilized with HP-HKUST-1. It can be calculated that the ratio of mesopore volume $\left(\mathrm{V}_{\text {meso }}\right)$ to micropore volume $\left(\mathrm{V}_{\text {micro }}\right)$ for HP-HKUST-1/PES membrane was about 3 times higher than that of HKUST-1/PES membrane, although the BET surface area and total pore volume decreased. 

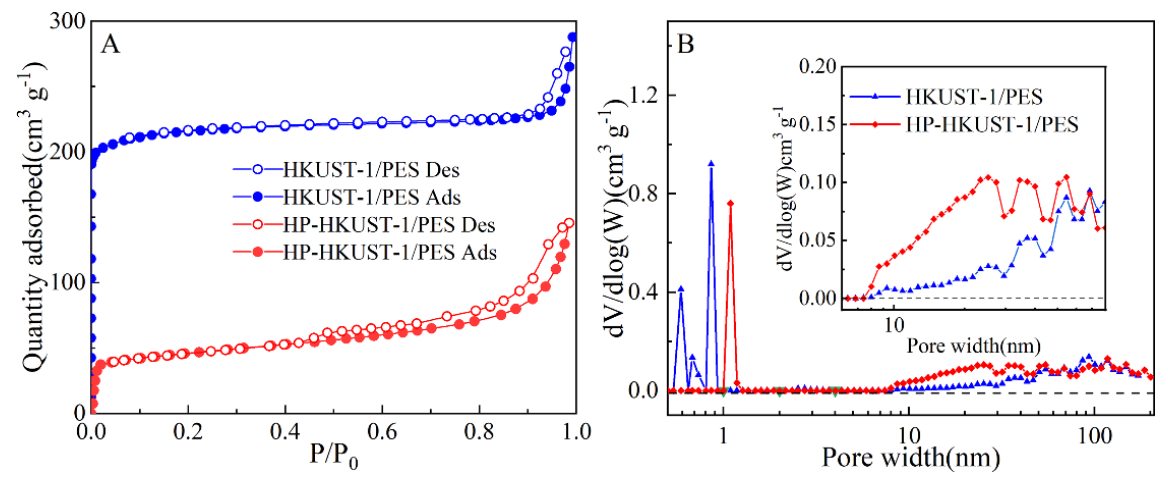

Figure $5 . \mathrm{N}_{2}$ adsorption-desorption isotherm curves (A) and pore distribution (B)of HKUST-1/PES membrane and HP-HKUST-1/PES membrane.

Table1 . Surface area and pore volume of membrane adsorber.

\begin{tabular}{lllll}
\hline Membrane & $S_{B E T}\left[\mathrm{~m}^{2} \mathrm{~g}^{-1}\right]$ & $V_{t}\left[\mathrm{~cm}^{3} \mathrm{~g}^{-1}\right]$ & $V_{\text {meso }}\left[\mathrm{cm}^{3} \mathrm{~g}^{-1}\right]$ & $V_{\text {meso }} / V_{\text {micro }}$ \\
\hline HKUST-1/PES & 432 & 0.43 & 0.13 & 0.43 \\
HP-HKUST-1/PES & 284 & 0.20 & 0.12 & 1.50 \\
\hline
\end{tabular}

\subsection{Improved adsorption performance}

The adsorption performance of membrane adsorber with $\mathrm{CR}$ and $\mathrm{MB}$, as well as its kinetic parameters are shown in Figure 6 . The specific details of the kinetic model parameters are illustrated in Table S1 . It can be seen that compared with the HKUST-1 powder, the adsorption capacity and the adsorption rate of the HP-HKUST-1 powder for CR and MB can be increased obviously. Specifically, for the HP-HKUST-1 powder, the adsorption capacity $\left(q_{t}\right)$ for $\mathrm{CR}$ with $458 \mathrm{mg} \mathrm{g}^{-1}$ and for $\mathrm{MB}$ with $227 \mathrm{mg} \mathrm{g}^{-1}$ can be achieved within $70 \mathrm{~min}$. However, for the HKUST-1 powder, the adsorption capacity for CR with only $155 \mathrm{mg} \mathrm{g}^{-1}$ and for MB with only $90 \mathrm{mg} \mathrm{g}^{-1}$ can be achieved within $70 \mathrm{~min}$. Compared with the HKUST-1 powder , the equilibrium adsorption capacity $\left(q_{e}\right)$ for both $\mathrm{CR}$ and $\mathrm{MB}$ can be increased about three times by the HP-HKUST-1 powder. In term of the adsorption rate constant $\left(k_{2}\right)$, the value can be increased about twice for both $\mathrm{CR}$ and $\mathrm{MB}$ adsorption. The increase of the adsorption capacity can be attributed to the increase of the adsorption active sites after the mesopores introduced into HKUST-1. The adsorption by HKUST-1 for $\mathrm{CR}$ and MB is mainly based on the formation of hydrogen bonds between the open oxygen active sites and the adsorbate, the superposition of van der Waals forces, electrostatic forces, $\pi-\pi$ bonds, as well as the coordination bonds between the unsaturated metal copper ion active sites of HKUST-1 and the adsorbates, as shown in Figure $\mathbf{7}^{28}$. The surface area of the HKUST-1 can be increased after the introduce of the mesopores in HKUST-1, leading to the increase of adsorption amount for CR and MB owing to van der Waals forces and electrostatic forces. More unsaturated metal active sites and oxygen active sites can be exposed as mesopores introduced into HKUST-1, leading to an additional adsorption amount owing to hydrogen bonds and coordination bonds as shown inFigure 7 . Specifically, for $\mathrm{CR}$ adsorption, more unsaturated $\mathrm{Cu}^{2+}$ are appeared as lattice vacancies generated in the topological structure of HP-HKUST-1, leading an additional adsorption interaction produced by coordination bond between $\mathrm{Cu}^{2+}$ and the $\mathrm{N}$ and $\mathrm{O}$ atoms of $\mathrm{CR}$ set off. Besides, the interaction of electrostatic forces between $\mathrm{Cu}^{2+}$ and the $-\mathrm{SO}_{3}{ }^{-}$of $\mathrm{CR}$ can be enhanced as a lager surface area of HP-HKUST-1. Moreover, the interaction of $\pi-\pi$ bonds can be also enhanced since volume-filling adsorption can occur during the adsorption of HP-HKUST-1 in addition to monolayer and multilayer adsorption with the introduce of mesopores ${ }^{29}$. For MB adsorption, coordination bond between $\mathrm{Cu}^{2+}$ and the $\mathrm{N}$ atoms of MB will occur with the introduce of mesopores. In addition, the interaction of $\pi-\pi$ bonds can be enhanced for the reason of volume-filling adsorption. 

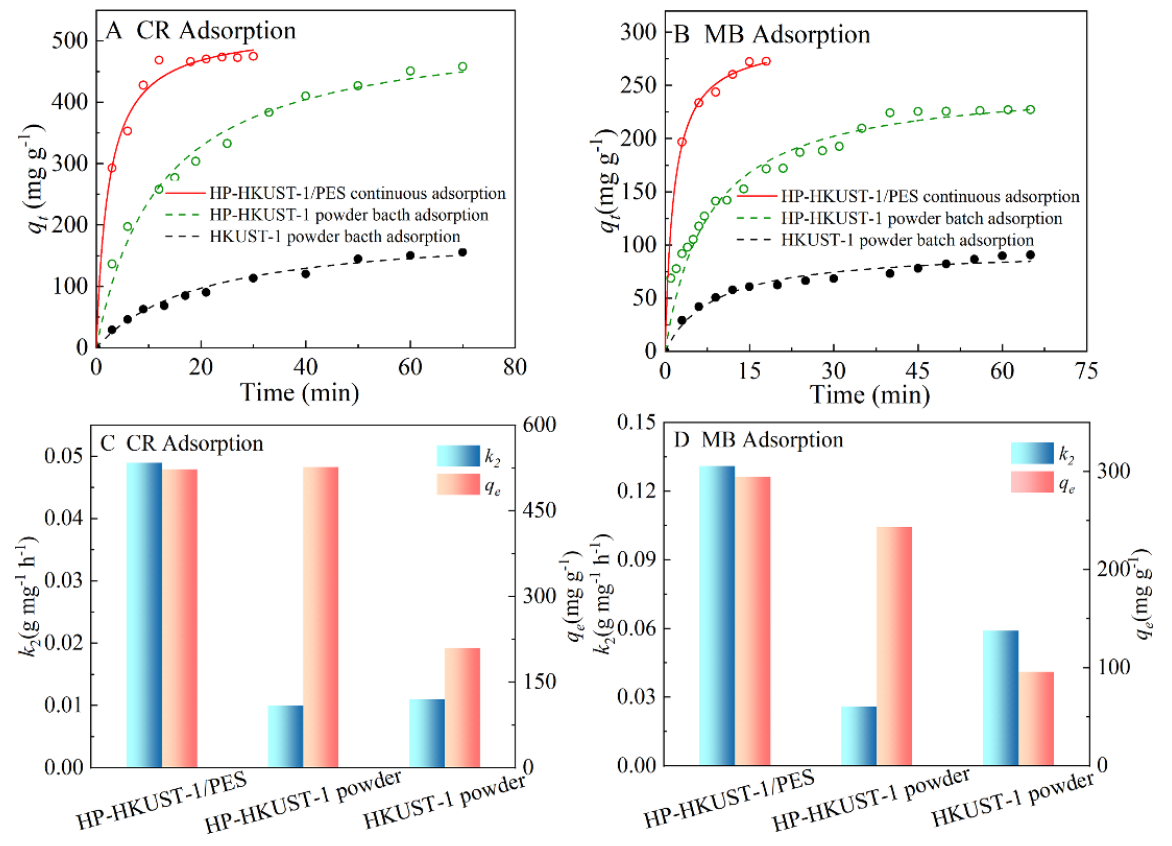

Figure 6 . Adsorption property of HP-HKUST-1/PES membrane (A, C: the adsorption curves and the adsorption kinetic models of powders and membrane adsober for CR adsorption; B, D: the adsorption curves and the adsorption kinetic models of powders and membrane adsorber for MB adsorption; concentration and volume of CR and MB solution: $200 \mathrm{mg} \mathrm{L}{ }^{-1}, 80 \mathrm{~mL}$, mass of the HKUST-1 and HP-HKUST-1 powders: $\left.0.015 \mathrm{~g} ; 20^{\circ} \mathrm{C}\right)$.

The increase of the adsorption rate can be attributed to the increase diffusion of the $\mathrm{CR}$ and $\mathrm{MB}$ to the adsorption active sites in HP-HKUST-1. It has been reported that the hierarchically porous structure facilitates the diffusion of the guest molecules within the pores and has a smaller diffusion limit ${ }^{30}$. In other words, mesoporous adsorption provides a larger concentration gradient for secondary multilayer adsorption and provides conditions for capillary coalescence, with mass transfer enhanced. Compared with the powdered HKUST-1, CR and MB can diffuse in the mesopores of powdered HP-HKUST-1 and the required time for $\mathrm{CR}$ and $\mathrm{MB}$ moved to the adsorption active sites can be shortened, leading to the increase of the adsorption rate.

From Figure 6 , it can be also seen that the adsorption rate by HP-HKUST-1/PES membrane is faster than that by the HP-HKUST-1 powder while the increase of adsorption capacity is not obviously. Specifically, the adsorption capacity of HP-HKUST-1/PES membrane for CR with $474 \mathrm{mg} \mathrm{g}^{-1}$ and for MB with $272 \mathrm{mg} \mathrm{g}^{-1}$ can be achieved within $20 \mathrm{~min}$. It can be deduced that the adsorption rate constant can be increased about three times for CR adsorption and five times for MB adsorption, after the HP-HKUST powder is immobilized in membrane pores under the condition of adsorption carried out in the flow-through mode. Enhanced contact and mass transfer are the two contributors for the faster adsorption by membrane adsorber, as described in our previous research ${ }^{16-22}$. The aggregation of the nano HP-HKUST-1 powder can be prevented beyond the scale of membrane pore size. Therefore, the active sites for adsorption on the surface of the nano HP-HKUST-1 powder can be exposed more, leading to the contact between the CR or MB and the HP-HKUST-1 enhanced. However, the quantity of active sites (on surface and at the inner) for adsorption cannot be increased just by avoid of aggregation. So, the adsorption capacity of the membrane adsorber can be hardly increased compared with the powder. During the process of adsorption by membrane adsorber with flow-through mode, the mass transfer is performed in the membrane pores and the distance of the mass transfer can be reduced to nano scale. Compared with the adsorption by powder, the resistance of the mass transfer in membrane pores can be reduced significantly. Therefore, the adsorption rate can be improved 
significantly by membrane adsorber.

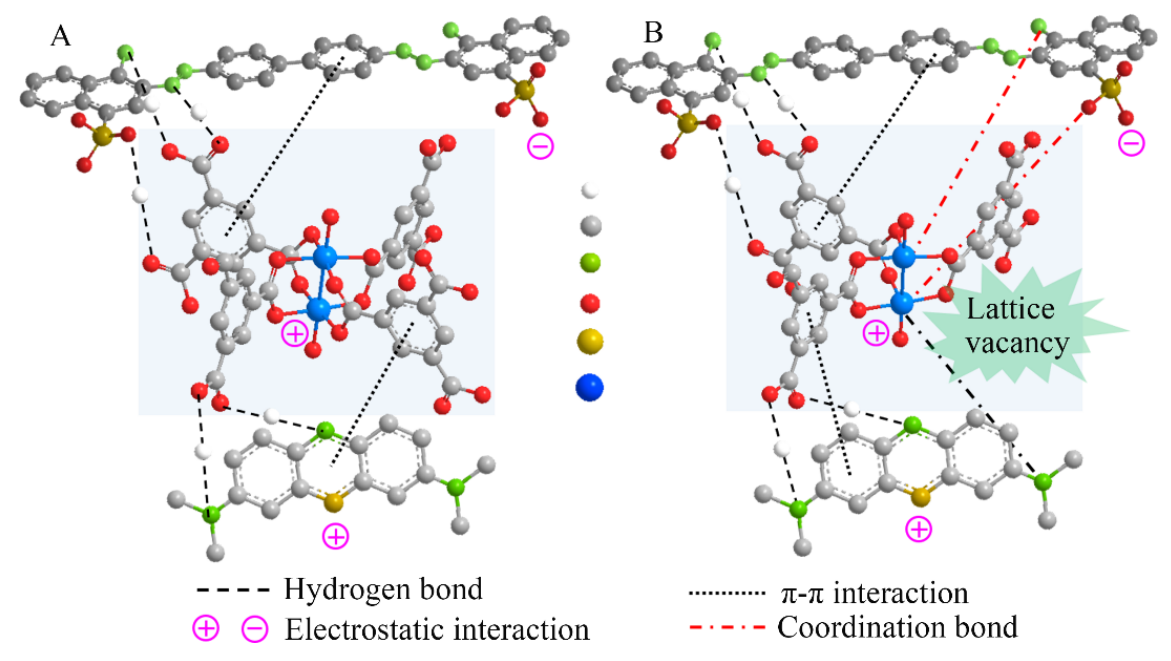

Figure 7. Mechanism of the adsorption of CR and MB by HKUST-1 (A) and HP-HKUST-1 (B).

In order to determine the diffusion mechanism of $\mathrm{CR}$ and $\mathrm{MB}$ during adsorption, the adsorption performance is described by the Weber-Morris intraparticle diffusion model, as shown in Figure $\mathbf{8}$. In general, three stages are included during the adsorption process by a porous material: outer diffusion process, inner diffusion process and intrinsic diffusion process. From Figure $\mathbf{8}$, it can be seen that the adsorption for CR by HKUST1 or HP-HKUST-1 can be only divided into two steps owing to the indistinct inner diffusion stage and the adsorption for MB can be divided into three steps. In other words, CR can be only adsorbed on the surface of the HKUST-1 or HP-HKUST-1 while MB can diffuse into the micropores of HKUST-1 or HP-HKUST-1. The difference of diffusion mechanism for $\mathrm{CR}$ and $\mathrm{MB}$ adsorption can be attributed to the different molecular sizes of CR and MB. The molecular size of CR $(2.29 \times 0.82 \times 0.60 \mathrm{~nm})$ is larger than the micro-pore size of HKUST-1 or HP-HKUST-1 $(0.8 \mathrm{~nm}){ }^{31,32}$. Thus, CR cannot diffuse into the micro-pores of HKUST-1 or HP-HKUST-1. Compared with RB, the molecular size of MB $(1.26 \times 0.77 \times 0.65 \mathrm{~nm})$ is smaller and CR can enter the micro-pores of HKUST-1 or HP-HKUST- $1^{33}$. The introduce of mesopores can provide more unsaturated $\mathrm{Cu}^{2+}$ and oxygen adsorption sites generated with the exfoliation of the template agent. Thus, compared with HKUST-1/PES membrane, the adsorption capacity for MB by HP-HKUST-1/PES membrane can be improved.
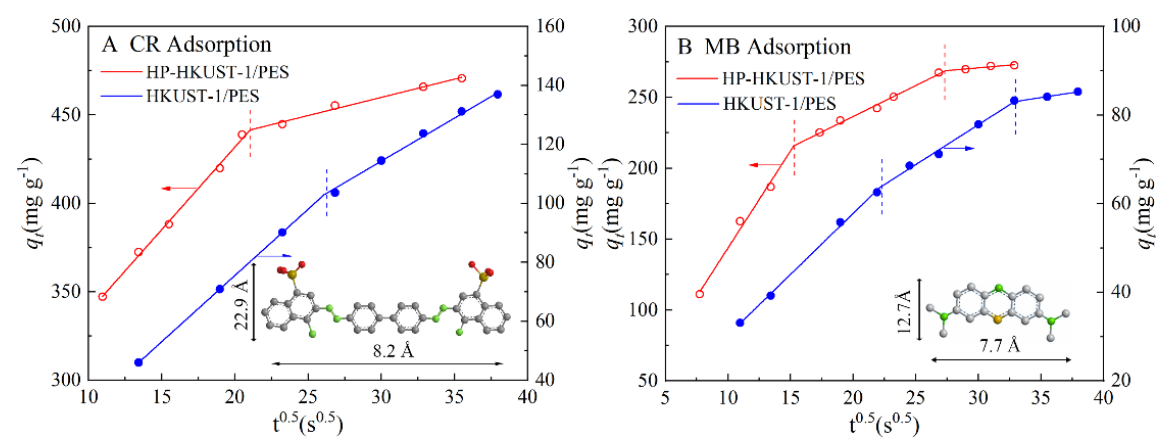

Figure 8 . The Weber-Morris intraparticle diffusion model for adsorption of $\mathrm{CR}(\mathrm{A})$ and $\mathrm{MB}$ (B) by HKUST-1/PES membrane and HP-HKUST-1/PES membrane (concentration and volume of CR and MB solution: $200 \mathrm{mg} \mathrm{L}{ }^{-1}, 80 \mathrm{~mL}$, mass of the HKUST-1 and HP-HKUST-1 powders: $0.015 \mathrm{~g} ; 20^{\circ} \mathrm{C}$ ). 


\subsection{Effect of parameters on adsorption}

During the process of membrane adsorber for CR and MB, the adsorption performance would be affected by some key parameters such as the concentration of $\mathrm{CR}$ and $\mathrm{MB}$ and the flowrate of the liquid flowing through the membrane. The effect of $\mathrm{CR}$ and $\mathrm{MB}$ concentration on adsorption is illustrated in Figure. 9(A, B) . It can be seen that higher capacity can be achieved under the condition of higher concentration of CR and MB. Besides, it can be also seen that the mesopores introduction would promote adsorption more obviously under the higher concentration of CR and MB. For example, the capacity of CR can be increased from $207 \mathrm{mg}$ $\mathrm{g}^{-1}$ by HKUST-1 powder to $523 \mathrm{mg} \mathrm{g}^{-1}$ by HP-HKUST-1 powder under the condition of CR concentration being $250 \mathrm{mg} \mathrm{L}^{-1}$. On the contrary, the capacity can be only increased from $97 \mathrm{mg} \mathrm{g}^{-1}$ by HKUST-1 powder to $291 \mathrm{mg} \mathrm{g}^{-1}$ by HP-HKUST-1 powder under the condition of CR concentration being $50 \mathrm{mg} \mathrm{L}^{-1}$. It can be deduced that the increased capacity being $316 \mathrm{mg}$ g- 1 can be achieved under the condition of higher CR concentration but the increased value of only about $194 \mathrm{mg} \mathrm{g}^{-1}$ is obtained under the condition of lower CR condition.

The effect of flowrate and mass of HP-HKUST-1 on the adsorption of CR and MB by HP-HKUST-1/PES membrane is presented in Figure 9(C, D ) and Figure S3 . It can be seen that the adsorption rate constant can be increased significantly with the increase of flowrate while the capacity can be hardly affected by the flowrate. It can be calculated that the adsorption rate constant for CR by HP-HKUST-1/PES membrane can be increased from $0.0045 \mathrm{~g} \mathrm{mg}^{-1} \mathrm{~h}^{-1}$ under the condition of flowrate of being $20 \mathrm{~mL} \mathrm{~min}^{-1}$ to $0.0774 \mathrm{~g} \mathrm{mg}^{-1} \mathrm{~h}^{-1}$ under the condition of flowrate of being $60 \mathrm{~mL} \mathrm{~min}^{-1}$. The corresponding value for MB adsorption can be increased from $0.0196 \mathrm{~g} \mathrm{mg}^{-1} \mathrm{~h}^{-1}$ to $0.114 \mathrm{~g} \mathrm{mg}^{-1} \mathrm{~h}^{-1}$. High adsorption rate obtained by flowrate increase can be attributed to the enhanced mass transfer rate in the micro or nano scale membrane pores. The rate of mass transfer may be relatively lower and the CR and MB molecules cannot be replenished in time due to the relatively higher intrinsic adsorption rate, if the flowrate is low. Thus, a thicker boundary layer around the adsorbate nanoparticles may be formed and the concentration of the CR and MB on the surface of HPHKUST-1 would be lower than that of the bulk solution, leading to the adsorption rate limited. The mass transfer would be enhanced with the boundary layer being thinner under the condition of higher flowrate. In this case, the fresh CR and MB molecules transferred to the surface of the HP-HKUST-1 could be promoted, leading to the adsorption rate increased.
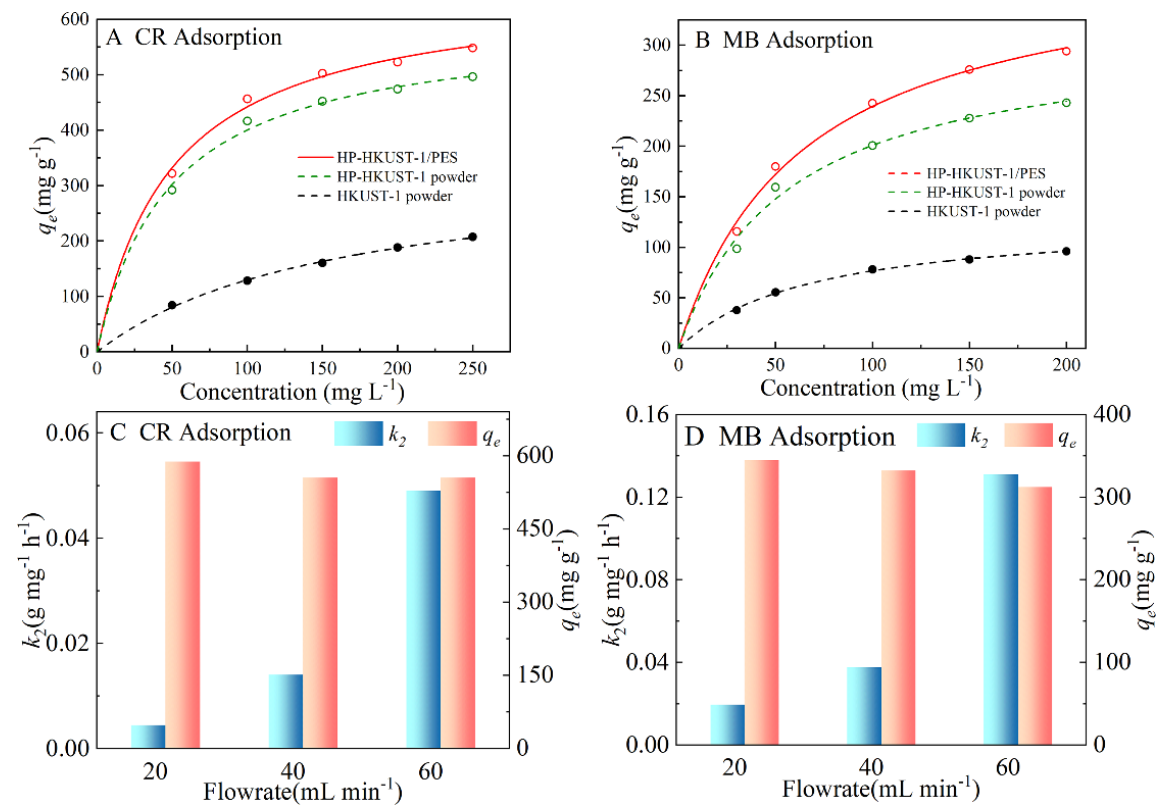

Figure 9 . Effect of concentration and flowrate on the adsorption for CR (A, C) and MB (B, D) by HP- 
HKUST-1/PES membrane (concentration and volume of CR and MB solution: $200 \mathrm{mg} \mathrm{L}^{-1}, 80 \mathrm{~mL}$, mass of the HP-HKUST-1 powders: $0.015 \mathrm{~g} ; 20^{\circ} \mathrm{C}$ ).

\subsection{Enhanced repeatability}

The repeatability of HP-HKUST-1/PES membrane is shown in Figure 10. The adsorption performance of the membrane adsorber is stable. It can be calculated that the adsorption capacity for CR and MB by the HP-HKUST-1/PES membrane are only decreased by $36 \%$ and $31 \%$ after seven cycles of adsorptiondesorption experiments. The adsorption of CR and MB by HP-HKUST-1/PES membrane owing to the physical adsorption such as van der Waals forces, electrostatic forces and $\pi-\pi$ bonds can be eluted by dissolving membrane adsorber in methanol for desorption, leading to higher adsorption capacity after several adsorption cycles. However, the adsorption of CR and MB by HP-HKUST-1/PES membrane owing to the chemical adsorption such as coordination interaction cannot be eluted by the desorption process. In the case of CR adsorption, the unsaturated $\mathrm{Cu}^{2+}$ on the HP-HKUST- 1 can be chelated with the $-\mathrm{N}=\mathrm{N}$ - group and $-\mathrm{NH}_{2}$ group in $\mathrm{CR}^{34}$. In the case of $\mathrm{MB}$ adsorption, the unsaturated $\mathrm{Cu}^{2+}$ forms bonds by coordination with sulfur and nitrogen atoms in MB was the chemical adsorption. Besides, $\pi$ orbital electrons of the aromatic ring in $\mathrm{MB}$ enter the $4 \mathrm{~s}$ vacant orbital of $\mathrm{Cu}^{2+}$ to form $\sigma$ bonds, while electrons of the $3 \mathrm{~d}$ orbital of $\mathrm{Cu}^{2+}$ enter the anti- $\pi$ orbital $\left(\pi^{*}\right)$ of the aromatic ring to form $d-\pi^{*}$ antibonding ${ }^{35,36}$. The high stabilization energy of the antibonding also increase the difficulty of MB desorption.

From Figure 10, it can be also seen that the decrease tread of adsorption capacity for CR and MB by HKUST-1/PES membrane is not as obvious as that of HP-HKUST-1/PES membrane, since the adsorption active sites provided for chemical adsorption is much less than that of HP-HKUST-1. Besides, the adsorption active sites provided for physical adsorption owing to the larger surface of the HP-HKUST-1 leads to the adsorption for CR and MB by HP-HKUST-1/PES membrane still much higher than that by HKUST-1/PES membrane. During the process of repeating adsorption-desorption experiments, it was found that there is no HP-HKUST-1 leaching from the membrane pores under the inertial and van der Waals forces as interfacial interactions between the nanoparticles and the membrane. Thus, it can be deduced that the decrease of adsorption capacity for $\mathrm{CR}$ and $\mathrm{MB}$ after several adsorption-desorption experiments is only due to the decrease of adsorption active sites provided for chemical adsorption and the capacity owing to the physical adsorption can be kept stably for a long time
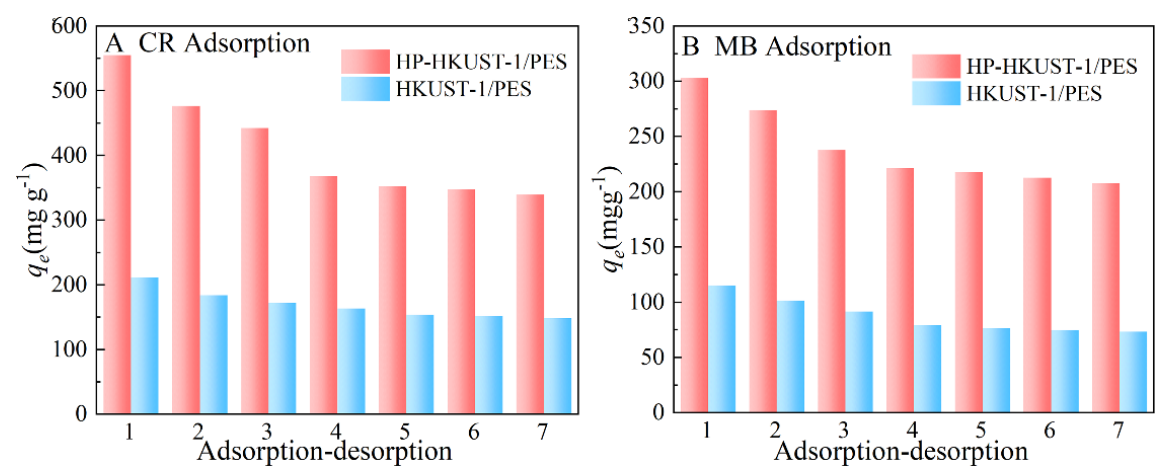

Figure 10 . Adsorption-desorption cycle of CR (A) and MB (B) by HKUST-1/PES membrane and HPHKUST-1/PES membrane (concentration and volume of $\mathrm{CR}$ and $\mathrm{MB}$ solution: $200 \mathrm{mg} \mathrm{L}^{-1}, 80 \mathrm{~mL}$, mass of the HKUST-1 and HP-HKUST-1 powders: $0.015 \mathrm{~g} ; 20^{\circ} \mathrm{C}$ ).

\section{Conclusions}

A membrane adsorber with HP-HKUST-1 has been fabricated by flowing synthesis for CR and MB adsorption. The mesopores of the HP-HKUST-1 can increase the adsorption active sites and enhanced mass 
transfer can be achieved in the confined space of the membrane pores during the adsorption process under the flow-through mode. The structures of the membrane adsorber have been characterized by XRD, XPS, FTIR, SEM, TEM and BET, which determined the successful immobilization of HP-HKUST-1 in membrane pores. Compared with the HKUST-1 powder, the adsorption capacity and rate for these two dyes can be increased several times by membrane adsorber. The membrane adsorber with HP-HKUST-1 immobilized in membrane pores also shows a remarkable repeatability and has good potential in industrial application.

\section{Associated content}

The following files are available.

TGA curves of HKUST-1/PES and HP-HKUST-1/PES membrane (Figure S1 ); HP-HKUST-1 nanoparticle TEM morphology image (Figure S2 ); The fitting results of adsorption kinetics for CR and MB by HPHKUST-1 powders and HP-HKUST-1/PES membrane (Table S1 ); Effect of the mass of HP-HKUST-1 on the adsorption for CR and MB by HP-HKUST-1/PES membrane (Figure S3 ).

\section{Author contributions}

Ke Bai performs experiments, data analysis, figures plotting and manuscript writing with input from all coauthors; Senqing Fan leads the experiments design, formal analysis and contributes to manuscript writing, and is the project administration and leads the whole project; Zeyi Xiao leads the supervision and takes part in the and discussion of the project; Other coauthors contributed equally to this work on helping experiment and analysis.

\section{Acknowledgements}

The present work was supported by the National Nature Science Foundation of China (No. 21808144) and the Fundamental Research Funds for the Central Universities (No. 20822041B4013).

\section{Competing interests statement}

Declarations of interest: none

\section{Nomenclature}

\begin{tabular}{ll}
\hline$q_{t}$ & Adsorption capacity \\
\hline$q_{e}$ & Equilibrium adsorption capacity \\
$C_{0}$ & Concentration of the adsorbate \\
$C_{t}$ & Concentration of the dye at time $t$ \\
$m_{M O F}$ & Loading ratio of the MOFs in the adsorber \\
$V$ & Volume of the dye solution \\
$\varphi_{i}$ & Loading ratio of the MOFs in the adsorber \\
$m_{i}$ & Total mass of the membrane adsorber \\
$m_{0}$ & Mass of the pristine PES membrane \\
$k_{1}$ & Adsorption rate constant of the pseudo-first-order kinetic \\
$k_{2}$ & Adsorption rate constant of the pseudo-second-order kinetic \\
$k_{d}$ & Adsorption rate constant of the inter-particle diffusion model \\
$S_{B E T}$ & BET surface area \\
$V_{t}$ & Total pore volume \\
$V_{\text {meso }}$ & Mesopore volume \\
$V_{\text {micro }}$ & Micropore volume \\
\hline
\end{tabular}

\section{Subscripts and superscripts}




\begin{tabular}{ll}
\hline 0 & At the beginning of the adsorption process \\
\hline$t$ & Adsorption time \\
$e$ & At the time when adsorption equilibrium is obtained \\
meso & Mesopore \\
micro & Micropore \\
\hline
\end{tabular}

\section{References}

1. Zhu Q L; Xu Q. Metal-organic framework composites. Chem. Soc. Rev. 2014; 43 (16): 5468-512.

2. Chui S Y, Lo M F, Charmant J P H, et al. A Chemically Functionalizable Nanoporous Material $\left[\mathrm{Cu}_{3}(\mathrm{TMA})_{2}\left(\mathrm{H}_{2} \mathrm{O}\right)_{3}\right]_{\mathrm{n}}$.Science. 1999; 283 (5405): 1148-1150.

3. Eddaoudi; M. Systematic design of pore size and functionality in isoreticular MOFs and their application in methane storage.Science. 2002; 295 (5554): 469-472.

4. O'Keeffe M; Yaghi O M. Deconstructing the crystal structures of metal-organic frameworks and related materials into their underlying nets. Chem. Rev. 2012; 112 (2): 675-702.

5. Xuan W, Zhu C, Liu Y, et al. Mesoporous metal-organic framework materials. Chem. Soc. Rev. 2012; 41 (5): 1677-95.

6. Banerjee R, Phan A, Wang B, et al. High-Throughput Synthesis of Zeolitic Imidazolate Frameworks and Application to $\mathrm{CO}_{2}$ Capture. Science. 2008; 319 (5865): 939-943.

7. Li F, Zheng K, Zhang H, et al. Nanoscale Hierarchically Porous Metal-Organic Frameworks: Facile Synthesis, Mechanism Research, and Application. ACS Sustainable Chem. Eng. 2019; 7 (13): 11080-11087.

8. Wang H N, Liu F H, Wang X L, et al. Three neutral metal-organic frameworks with micro- and meso-pores for adsorption and separation of dyes. J. Mater. Chem. A. 2013; 1 : 13060-13063.

9. Jung B K, Jun J W, Hasan Z, et al. Adsorptive removal of p-arsanilic acid from water using mesoporous zeolitic imidazolate framework-8. Chem. Eng. J. 2015; 267 : 9-15.

10. Feng L, Wang K, Lv X, et al. Hierarchically porous metal-organic frameworks: synthetic strategies and applications. Natl. Sci. Rev. 2020; 7 (11): 1743-1758.

11. Guan H, LeBlanc R J, Xie S, et al. Recent progress in the syntheses of mesoporous metal-organic framework materials. Coord. Chem. Rev. 2018; 369 : 76-90.

12. Cai G R; Jiang H L. A Modulator-Induced Defect-Formation Strategy to Hierarchically Porous MetalOrganic Frameworks with High Stability.Angew. Chem. 2017; 56 : 563-567.

13. Y M, M A, K K, et al. The role of interparticle and external forces in nanoparticle assembly. Nat. Mater. 2008; $7:$ 527-538.

14. Huang N, Drake H, Li J, et al. Flexible and Hierarchical Metal-Organic Framework Composites for High-Performance Catalysis.Angew. Chem., Int. Ed. Engl. 2018; 57 (29): 8916-8920.

15. Li Y, Yuan D, Geng Q, et al. MOF-Embedded Bifunctional Composite Nanofiber Membranes with a Tunable Hierarchical Structure for High-Efficiency PM0.3 Purification and Oil/Water Separation.ACS Appl. Mater. Interfaces. 2021; 13 (33): 39831-39843.

16. Qiu B, Fan S, Chen Y, et al. Micro membrane absorber with deep-permeation nano structure assembled by flowing synthesis. AIChE J. 2021; 67 : e17272.

17. Qin Y, Jian S, Bai K, et al. Catalytic Membrane Reactor of Nano (Ag+ZIF-8)@Poly(tetrafluoroethylene) Built by Deep-Permeation Synthesis Fabrication. Ind. Eng. Chem. Res. 2020; 59 (21): 9890-9899. 
18. Qiu B, Fan S, Wang Y, et al. Catalytic membrane micro-reactor with nano ZIF-8 immobilized in membrane pores for enhanced Knoevenagel reaction of Benzaldehyde and Ethyl cyanoacetate. Chem. Eng. J.2020; $400: 125910$.

19. Chen Y, Fan S, Qiu B, et al. Enhanced Catalytic Performance of a Membrane Microreactor by Immobilizing ZIF-8-Derived Nano-Ag via Ion Exchange. Ind. Eng. Chem. Res. 2020; 59 (44): 19553-19563.

20. Denning S, Majid A A, Lucero J M, et al. Metal-Organic Framework HKUST-1 Promotes Methane Hydrate Formation for Improved Gas Storage Capacity. ACS Appl. Mater. Interfaces. 2020; 12 (47): $53510-53518$.

21. Chen Y, Fan S, Qiu B, et al. Cu-Ag Bimetallic Core-shell Nanoparticles in Pores of a Membrane Microreactor for Enhanced Synergistic Catalysis. ACS Appl. Mater. Interfaces. 2021;13 (21): 24795-24803.

22. Chen J, Fan S, Chen Y, et al. Electrocatalytic composite membrane with deep-permeation nano structure fabricated by flowing synthesis for enhanced catalysis. J. Membr. Sci. 2021; 636 : 119616.

23. Jiao C, Majeed Z, Wang G-H, et al. A nanosized metal-organic framework confined inside a functionalized mesoporous polymer: an efficient $\mathrm{CO}_{2}$ adsorbent with metal defects. J. Mater. Chem. A. 2018; 6 (35): $17220-17226$.

24. Li Y; Yang R T. Hydrogen storage in metal-organic and covalent-organic frameworks by spillover. AIChE J. 2008;54 (1): 269-279.

25. J E W, F H, E C, et al. Cobalt(ii), Nickel(ii), and Copper(ii) Complexes of 2-Methylimidazole. J. Chem. Soc. A. 1968: 128-132.

26. Qi L, Tang X, Wang Z, et al. Pore characterization of different types of coal from coal and gas outburst disaster sites using low temperature nitrogen adsorption approach. Int. J. Min. Sci. Technol. 2017; 27 (2): 371-377.

27. M T, K K, V N A, et al. Physisorption of gases, with special reference to the evaluation of surface area and pore size distribution (IUPAC Technical Report). Pure Appl. Chem. 2016; 87 : 1051-1069.

28. Ediati R, Laharto P B F, Safitri R, et al. Synthesis of HKUST-1 with addition of Al-MCM-41 as adsorbent for removal of methylene blue from aqueous solution. Mater. Today: Proc. 2021; 46 : 1799-1806.

29. $\mathrm{Lu} \mathrm{L}, \mathrm{Li} J, \mathrm{Ng} \mathrm{D} \mathrm{H} \mathrm{L}$, et al. Synthesis of novel hierarchically porous $\mathrm{Fe}_{3} \mathrm{O}_{4} @ \mathrm{MgAl}-\mathrm{LDH}$ magnetic microspheres and its superb adsorption properties of dye from water.J. Ind. Eng. Chem. 2017; 46 : 315323.

30. Tanev P T; Pinnavaia T J. A Neutral Templating Route to Mesoporous Molecular Sieves. Science. 1995; 267 (5199): 865-867.

31. Sulistiono D O, Santoso E; Ediati R. Enhanced Adsorption of Methylene Blue and Congo Red from Aqueous Solutions by MCM-41/HKUST-1 Composites. Asian J. Chem. 2019; 31 (8): 1675-1682.

32. Li F, Zheng K, Zheng X, et al. Facile Synthesis of Hierarchical Micro-mesoporous HKUST-1 Using Organic Silane Surfactant as a Novel Template. ChemistrySelect. 2019; 4 (7): 2079-2083.

33. Xin Z, Ying W, Cuimiao F, et al. Highly Efficient Adsorption of Bulky Dye Molecules in Wastewater on Ordered Mesoporous Carbons. Chem. Mater. 2009; 21 (4): 706-716.

34. Wang P, Gao Y, Wu Y, et al. Colorimetric Test Kit for Cu2+ Detection. Org. Lett. 2008; 10 (21): $5015-8$.

35. Hernández-Maldonado A J, Yang R T; Yang F H. Desulfurization of Transportation Fuels with Zeolites Under Ambient Conditions.Science. 2003; $301: 79$. 
36. Hernández-Maldonado A J; Yang R T. New sorbents for desulfurization of diesel fuels via $\pi$-complexation. AIChE J. 2004;50 (4): 791-801.

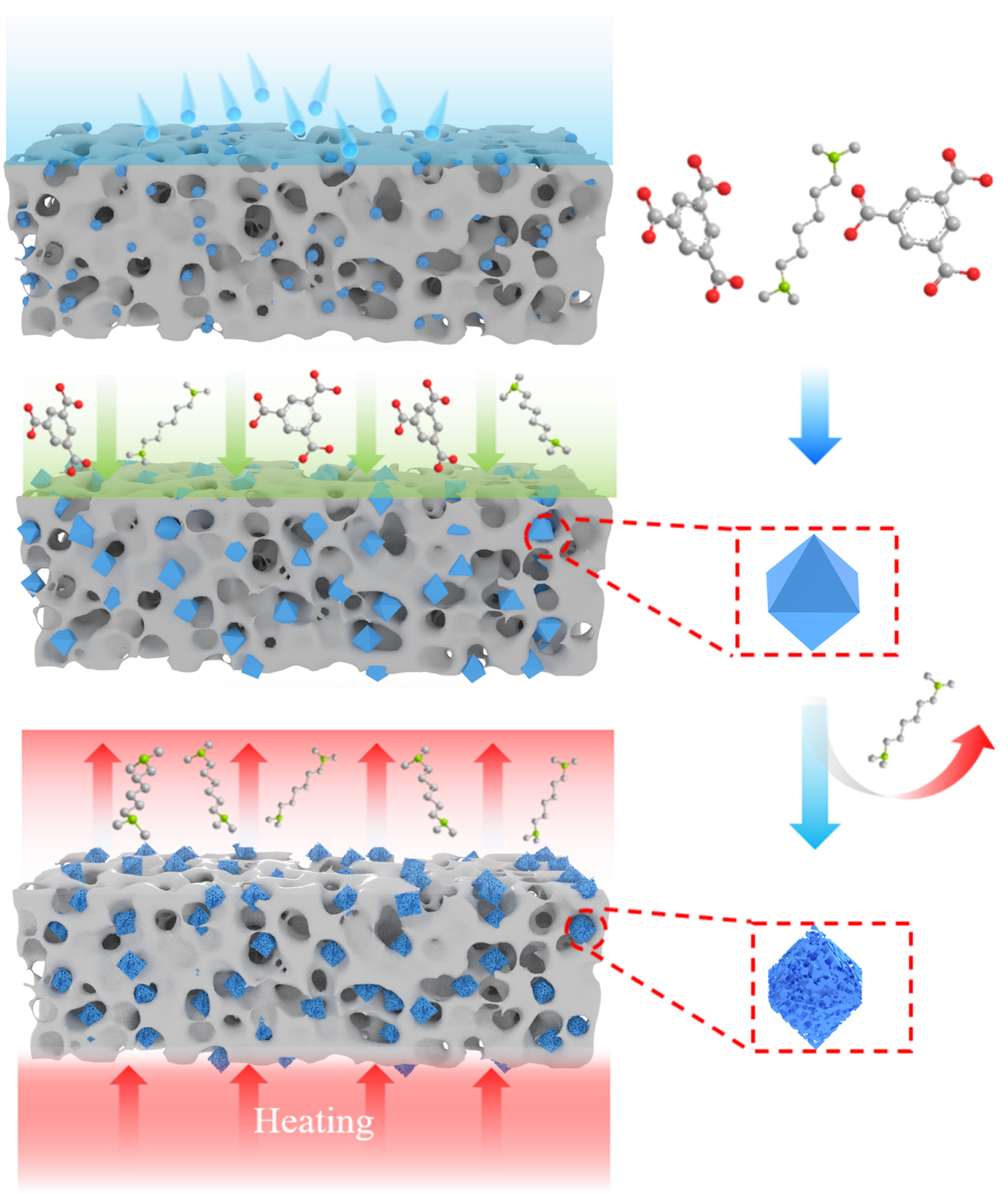




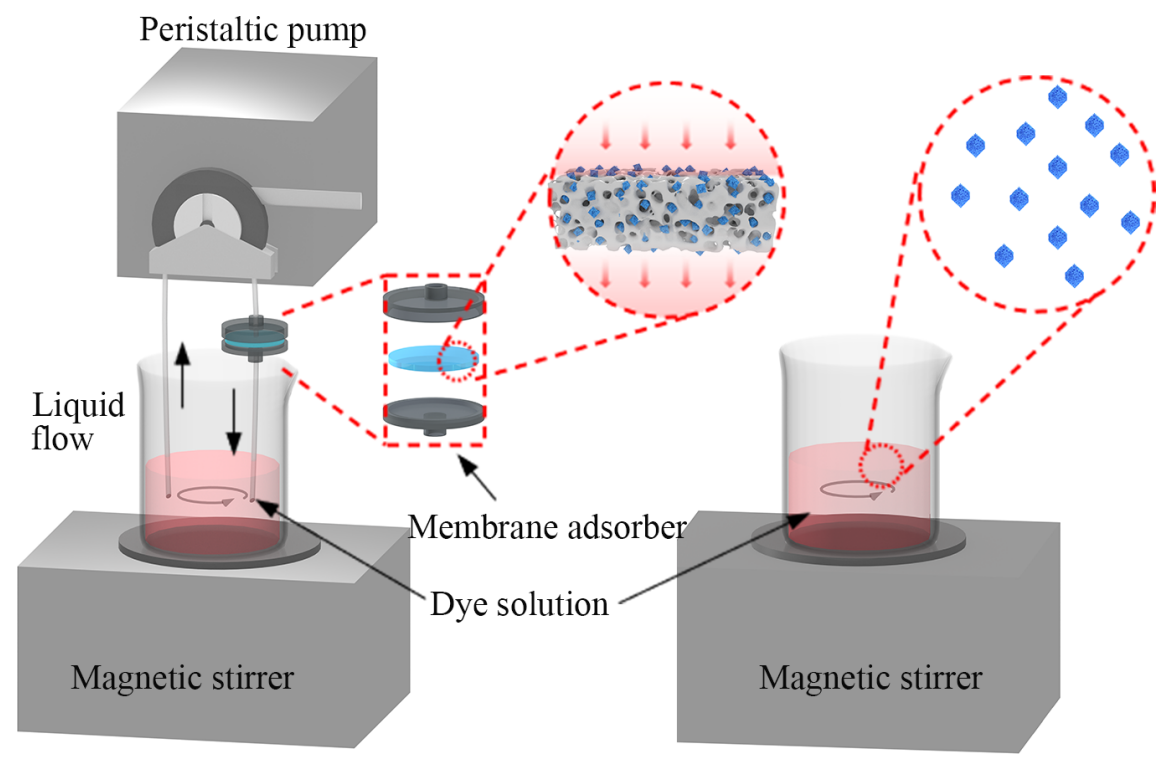

Continuous adsorption

Batch adsorption
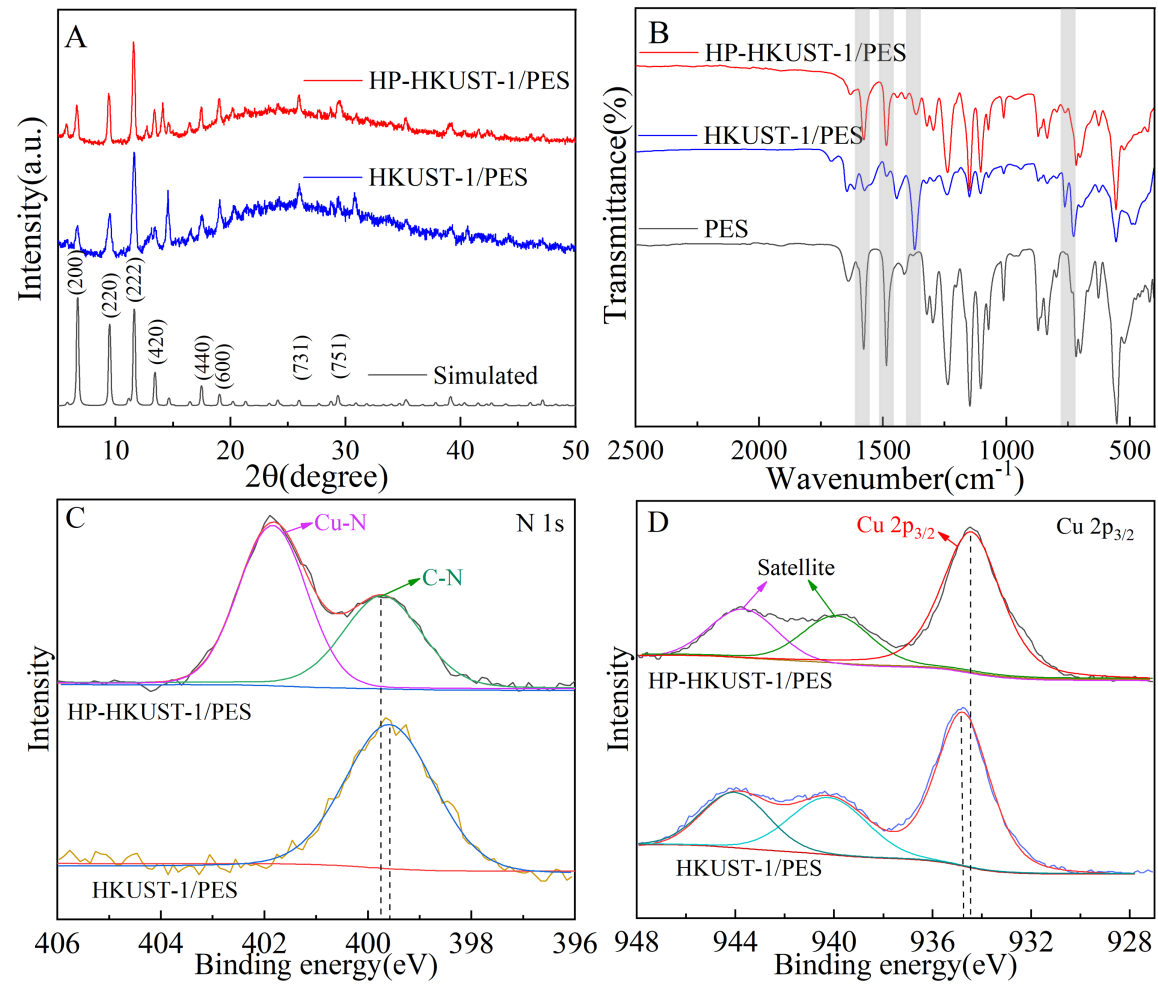





- - - - Hydrogen bond

$\oplus \ominus$ Electrostatic interaction


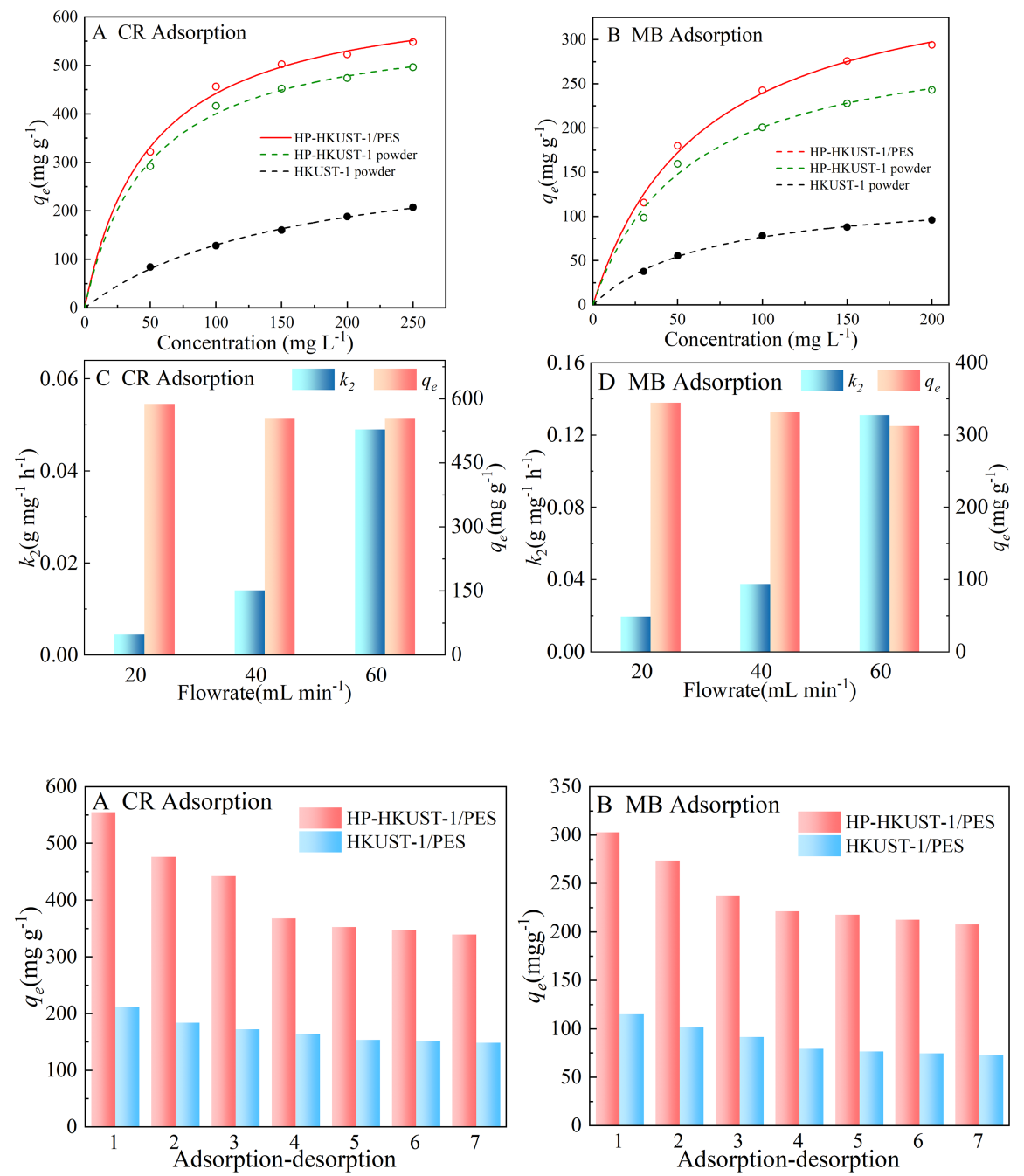